\title{
مفهوم الكتابة وتثكلاته في المشروع النقدي المعاصر
}

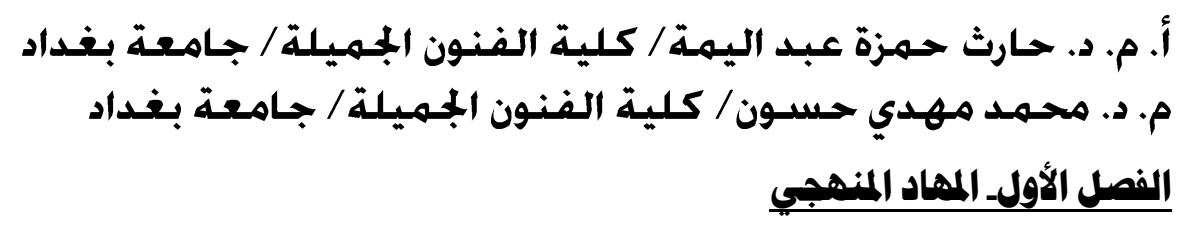

أولا: مشكلة البحث: ان العملية الإبداعية تستلزم خبرة عقلية وو عياً معرفياً في ادر اك ماهية الوجود وكنه الذات داخله بوصفه

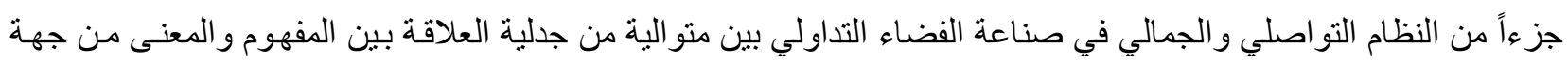

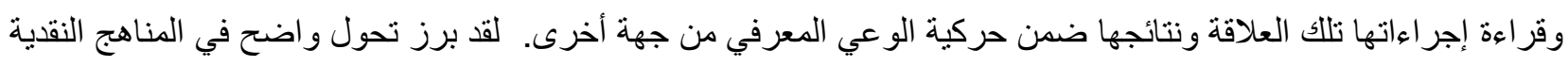

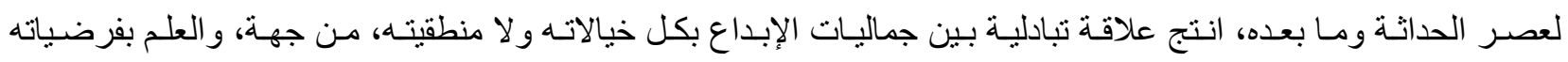

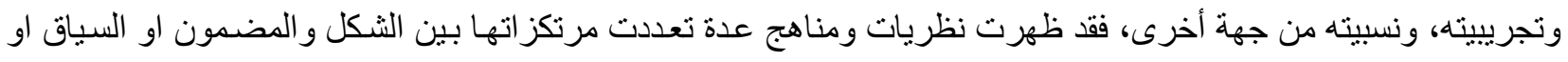

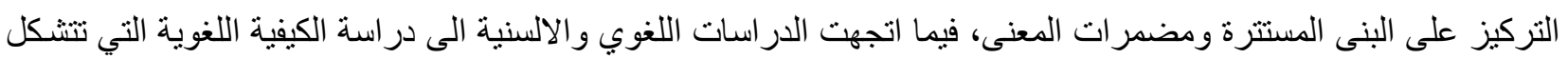

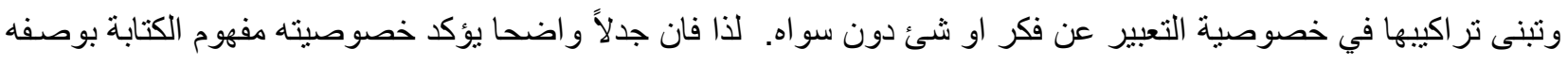

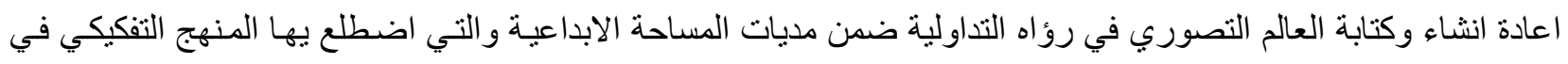

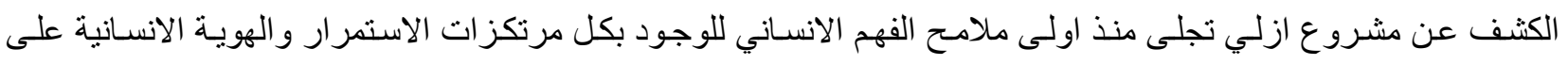

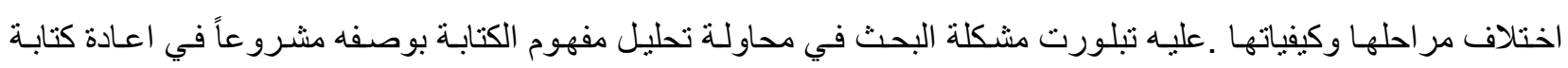

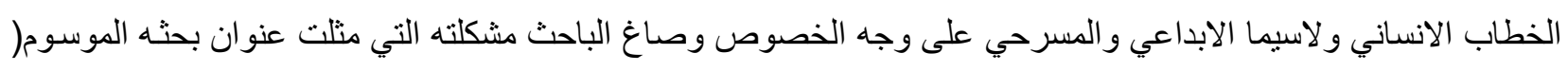
مفهوم الكتابة وتطبيقاته في الخطاب المسرحي.

ثانياً: الهية البحث : تأتي اهية البحث بوصفه محاولة للكثف عن مفهوم الكتابة وابعاده الاشتغالية على مستوى المنهج النقدي و الخطاب الابداعي. ثالثا: هدف البحث: التعرف الى مديات مفهوم الكتابـة بوصفه مرتكز اً نقدياً قائمـا على اعادة الفهم و الكتابة للعالم الانساني والابداعي ضمن معطياته الثقافية والمعنائية و التو اصلية المتمثلة بالمتلقي.

\section{المهاد النظري المبحث الأول: الكتابة (المهوم والإجراء):}

أو لاً: المفهوم: ان عمليات التحول المعرفي بين مر احل الفكر الإنساني أدت الى اختلاف مديات تصور العهالم العالم بمكونيه المعرفي

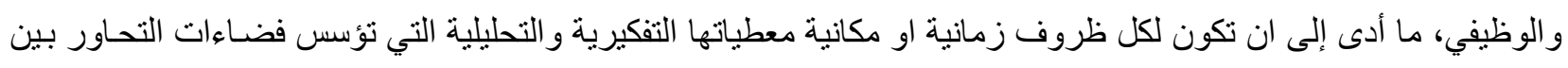
الذات بوصفها وعياً قر ائياً من جهة ومجمل العمليات الملامسة لمنظومة الاثر بمستوياته المتعددة وظو اهره المنتطرة و والمنبثقة

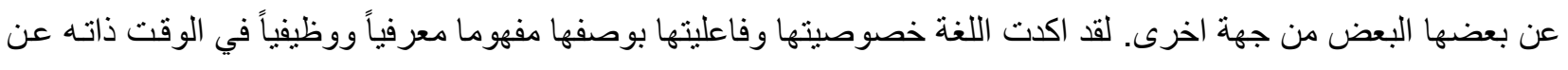
طريق منظومة من التعالقات الني انتجت عمليات التحديث و التنظيم المستمرة للنظام اللساني على المستوى الإبداعي او التحليلي الذي يعبر بطبيعة الحال عن فلسفة العصر بمجمل تحو لاته ضمن معطيات اللحظة الكتابية التي تحدث داخلها عملئيات معقدة ومتنو عة من القر اءات بهدف تفكيك الخطاب وتأسيس مجال من التفاعلات التداولية " تصبح اللغة في الممارسـة التفكيكية للعب

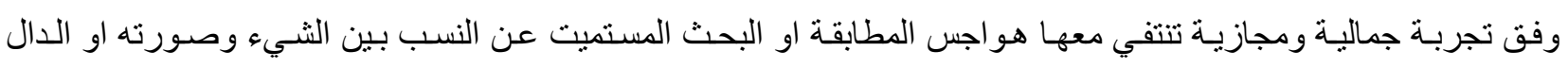

ومدلوله".(1)

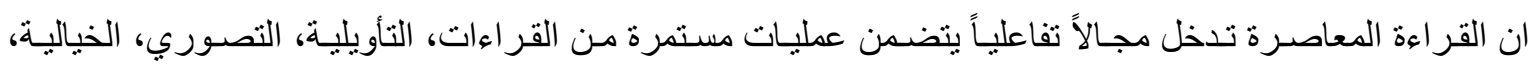

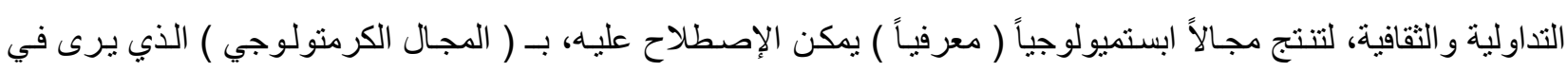


الوجود فعلاً مضار عاًً (r) يتوجب قر اءته وكتابته من جديد بطريقة مختلفة واسلوب مغاير يتتبع الاثر القرائي بهدف تحقق فعل الكتابة. والكتابة مفهوم إستر اتيجي في المنهج النقدي المعاصر، اقترحه الفرنسي ( جاك دريدا )، بوصفه فعلاً مقابلاً لفعل قر اءة

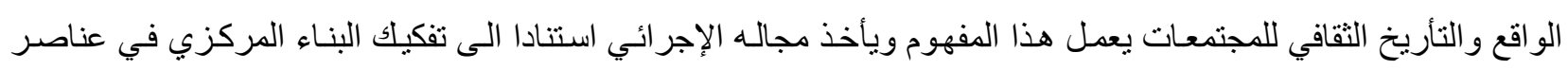
الخطاب الإبداعي و المسرحي على وجه الخصوص، وبالتالي فانه يقوم بخلق مجال من الاختلافات، الضمنية و السياقية، والتي يقوم على اساسها المنهج التفكيكي عند ( دريدا )" التفكيك هو بالضبط تحديد المنطق الانطولوجي واولاً تحديد الفعل الحاضر للثخص الثالث او الغائب س يكون ص (" ) ـ" فالكتابـة مفهوم يعتمد نسقاً شمولياً في منو اليـة من التتكلات غير المركزيـة و غير المستقرة او الثابتة فهي انثيالات مستمرة تجنمع في الهدف وتختلف في الطر ائق و الاشكال وقنوات التعبير ضمن حركية

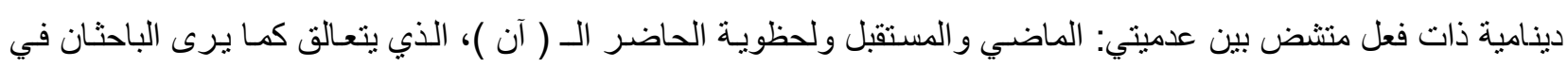
جو هره بمفاهيم عدة، لعل ابرزها: مفهوم الفكرة: إذ ان ثمة تعالقاً يعتمد استلهام الجوهر الإدر اكي للوعي عن طريق المعطى الفكري للنظام بمستوييه

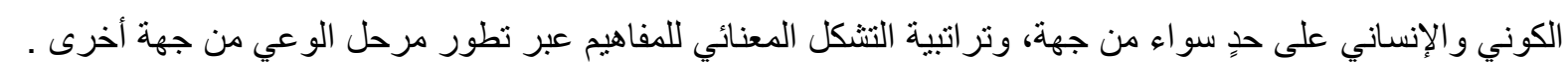
مفهوم اللغة: فالكتابة لغة تتعالق مع شتى اثكال النظامين: السببي و الوظيفي للوعي بمفهومه التفكيري . مفهوم التاريخ: فالكتابة انما هي تأصيل لفعل النفي الذي يقابل الاثبات في نفي المركزيـة التقليديـة للكتابـة بمفهومها النسقي و الافقي بقابله اثبات

\section{المبحث الثاني: هفهوم الكتابة في الاشتغال البمالي:}

ان الفعل الجمالي انما هو بنية حوارية نرتكز الى افعال التصور العلائقي لطبيعة الأنشطة الإنسـانية وتحولات الفكر

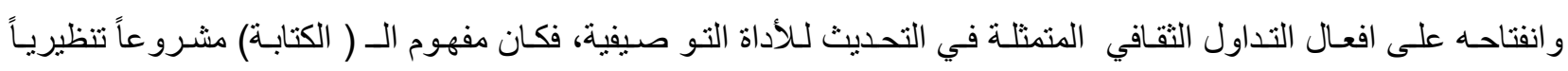

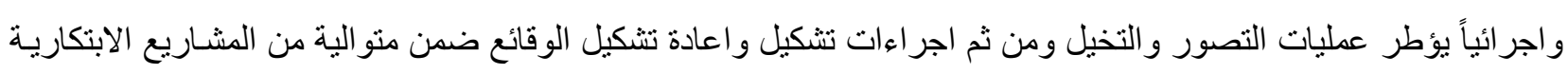

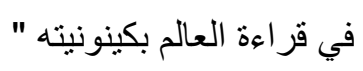

ان مجمل التمظهرات المنبثقة في صور العمل الفني على اختلاف كيفياته انمـا هي ضرب من قراءة الواقع بشكل

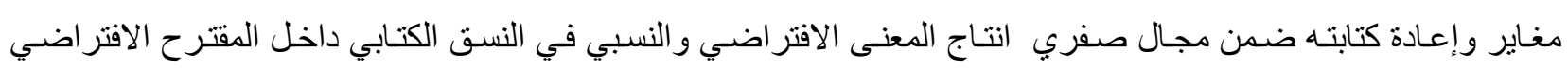

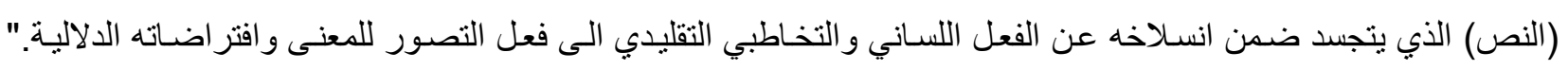

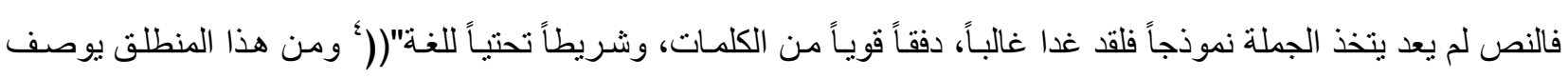
النص بانه فعل تو اصلي يتوسط المساحة القائمة بين الفضاءات المتعددة للمعنى بنو عيه الرئيسين:

$$
\text { الفضاء النأياء الايقوني بالمعنى السياقي مقابل فضاء الانفتاح }
$$

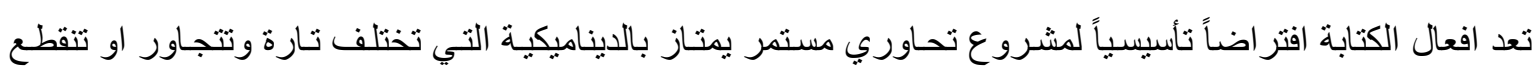

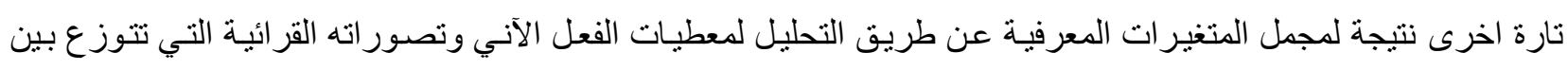
حقلين رئيسين: l. الكتابة ضمن اطار الفعل الابداعي ببعده التخيلي.

\section{$-917$.}




$$
\text { r. الكنابة ضمن اطار المنهج التنظيري متمثلاً بالمشروع النقدي. }
$$

ان العلاقة التفاعلية بين الكتابة الفنية و الكتابة النقدية تؤكد خصوصيتها في عمليات غير متتاهية من البحث في انظمـة

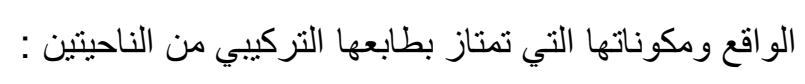

$$
\text { r. }
$$

تمثل ذلك بتعدد المقاربات التو اصلية في محاولة لإعادة تشكيل الو اقع انطلاقاً من محولة استيعاب النسق الموضوعي

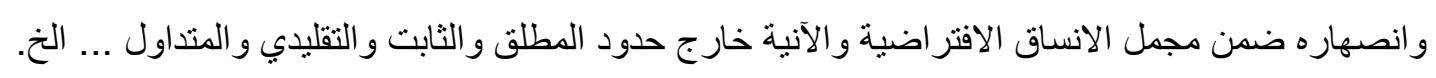
ان التحو لات المستمرة في مسيرة الوعي الانساني أنتجت مشروعاً يحمل طابع الحواريـة ومنطلقاته في الكثف عن التن

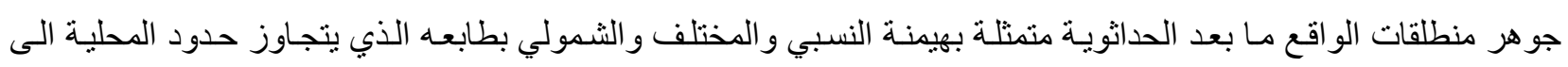
مساحة الفضاء التاويلي الذي يعني بالبحث في مفهوم المعنى و لا يعنى بالتفصيلات الدقيقة لتر اكيب تكون النظام. تمثل اللغة الكيان الأرحب الذي يسعى فيه الإنسان الى استيعاب أنساقها و عناصر ها بهدف تمكين الوعي من النواصل

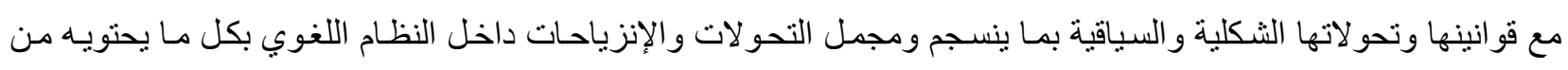

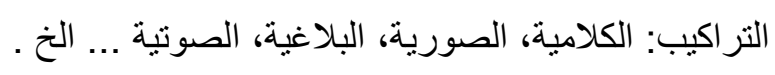
إذ تتشكل البنى اللغوية على وفق مستوبين من الأفعال هما

$$
\text { الأفعال المركزية. }
$$

عن طريق اعادة صناعة التاريخ بالنسبة للو اقع و انصهاره مع معطيات الفعل الثقافي للخطاب الانساني في مركزيـة

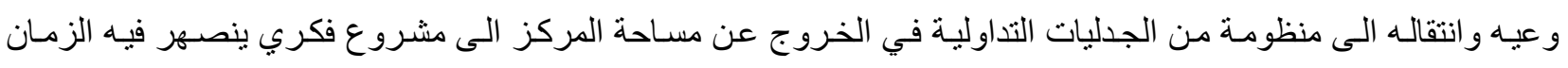
و المكان ضمن فضـاء مفهوم الكتابـة بشقيه " وكلمة مشروع project هي الكلمـة التي يفضلونها دعاة التفكيكية في وصفهر اعمال دريدا و القصد هي الالحاح على ان التفكيلك لا يمكن مناقتنه باستخدام ادوات العقل و التحليل المنطقي فهو يقتضي منطقاً

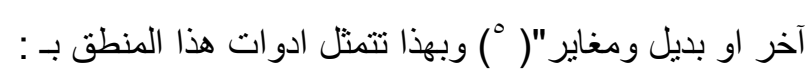

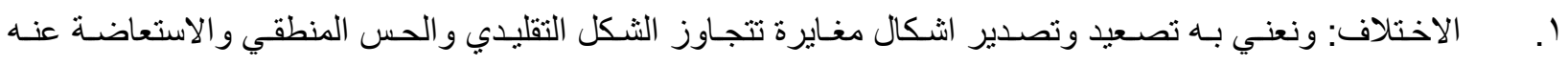

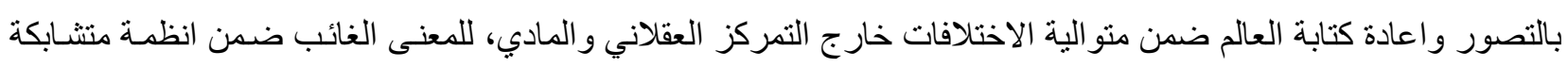

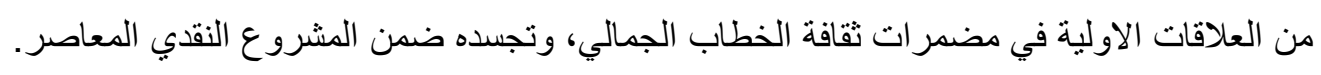

r. الإرجاء: المقصود به إضمار المعنى وتأجيله وعدم التصريح عن طريق تضمينه لككونات الخطاب ووحداته التركيبية التي تؤسس وتكرس مشروعية المشروع النقدي بوصفه منو اليـة من الحضور المختلف للوعي القر ائي، وغيابـات مستمرة

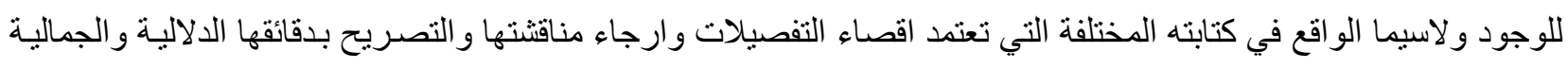

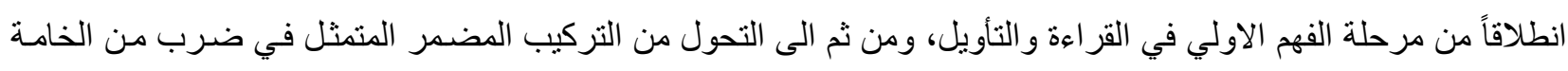

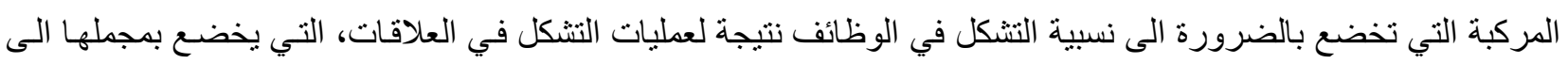
تأثيرات اللحظة التاريخية. 
وبعد التحقق من وجود المعنى فان مجمل العمليات التفكيرية تؤكد اشتمالها لمفهوم النص، بوصفه تركيباً شمولياً

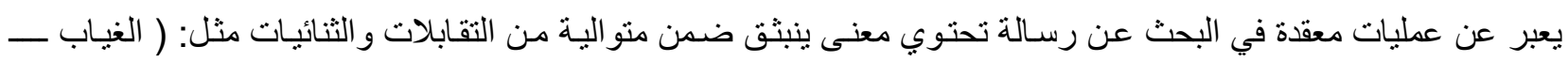
الحضور ، التجاور ات ـ الانقطاعات ، الظاهر ـ المضمر ، المركز ــ الهامش ... الخ )، فالعملية الانسانية عبر متو الياتها تثكل تر اكيباً دقيقة في صناعة الخطاب الجمالي علي المستويين: الابداعي و التنظيري ( النقدي ) من جهة، و والعلاقة التبادلية

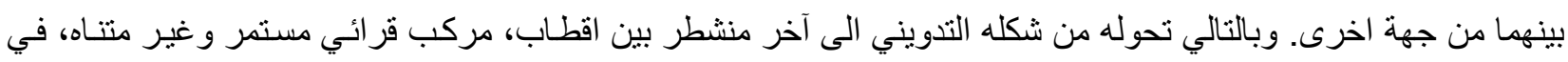

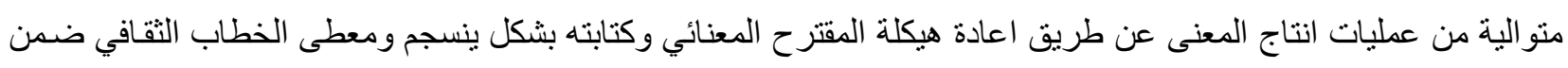

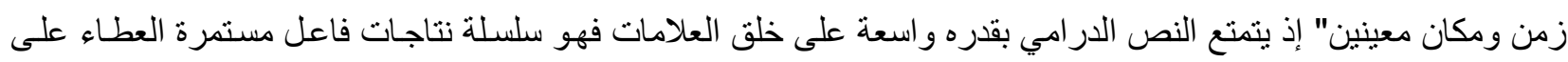

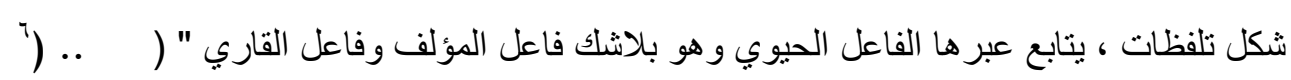
فعملية التحاور بين مكونـات الفضـاء التعايثـي للإنسـان بصفته الواعية، و انسـاق ذلك التحاور في تحققه على وفق جدليات التحاور و التطور التي ترنبط بضرورات اللحظة التاريخية، وما تؤكده اللغة بأنها شكل متحول ومتو الد، حتى تصل التهل مرحلة تتجاوز حدود المركز و المطلق الى مسـاحات الانفتاح غير المركزي و النسبية، حتى تصل مفهوم الكتابـة بصفته فعلاً

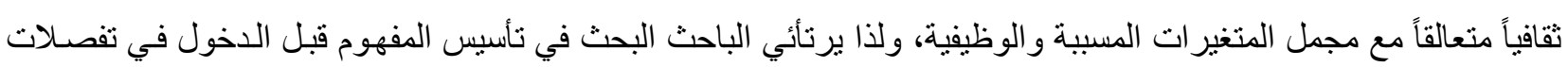

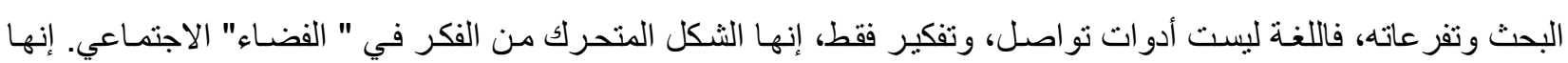

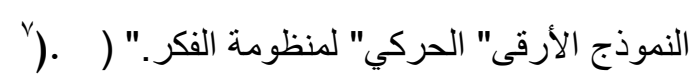
ما أسفر عنه المهاد النظري: -لكتابة مشروع تحاوري يعتمد نسقاً شمولياً في منو اليـة من التشكلات غير المركزيـة وغير المستقرة او الثابتة التي تتوزع بين: التاريخ و الثقافة و الوعي. - من هذا المنطلق يوصف النص بانه فعل نو اصلي يتوسط المساحة القائمة بين الفضاءات المتعددة للمعنى بنو عيه الرئيسين:

$$
\text { - الفضاء الايقوني بالمعنى السباقي }
$$

- يتشكل مفهوم الكتابة عن طريق اعادة صناعة التاريخ بالنسبة للو اقع و انصهاره مع معطيات الفعل الثقافي للخطاب الانساني في مركزية و عيه و انتقاله الى منظومة من الجدليات التداولية في الخروج عن مساحة المركز الى مشروع فكري ينصـهر فيه الزمان و المكان ضمن فضاء مفهوم الكتابة بشقيه :

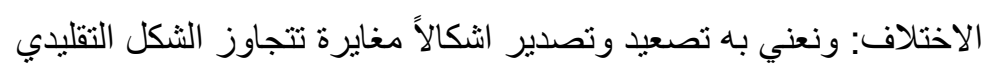
- الإرجاء: المقصود به إضمار المعنى وتأجيله وعدم التصريح عن طريق تضمينه لمكونات الخطاب ووحداته التركيبية

\section{الفصل الثالثـ اجراءات البحث:}

1. منهج البحث: يتمثل منهج البحث باعتماد الباحث للمنهج الوصفي في تحليل عينة بحثه.

r. عينة البحث: اعتمد الباحث عينة بحثه عددا من الدفاهيم النقدية و القرائية في عمليات تشكلها وتعالقها داخل مجال الكتابة تمثلت بالآتي: 


\begin{tabular}{|c|}
\hline الثقافة. \\
\hline المعنى. \\
\hline المتلقي. \\
\hline
\end{tabular}

r. طريقة اختيار العينة : نم اختيار عينة البحث بشكل قصدي منتخب على وفق منطلقات البحث واهدافه.

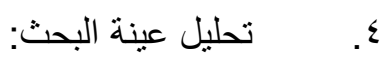

(النموذج رقم (1)

ا. . الثقافة: يعد مفهوم الثقافة احد المفاهيم التي برزت في شكل واضح في الألفية الثالثة لما يمتاز بـه من انفتاح

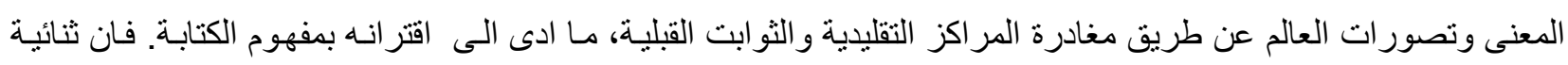

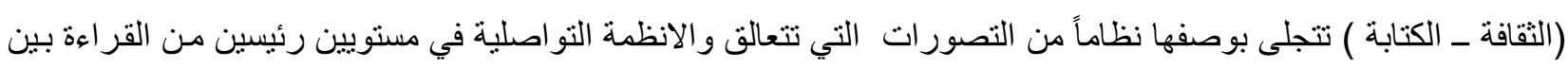

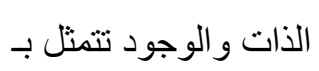

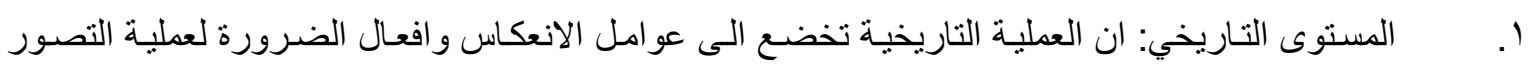

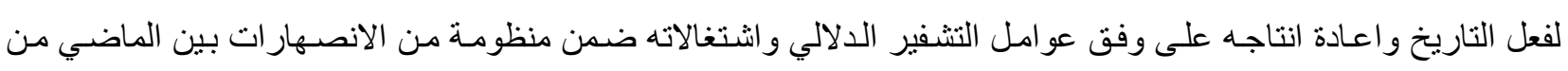

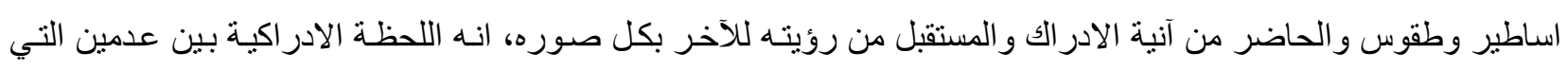
تستلهم القبلي و البعدي ضمن الـ ( آن ) و الـ ( هنا ).

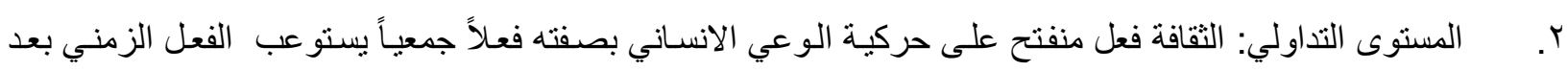

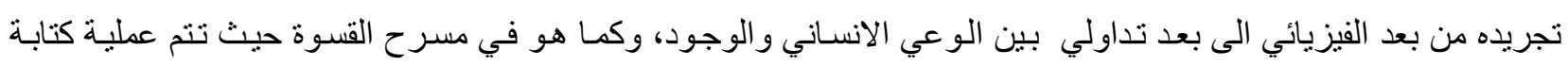

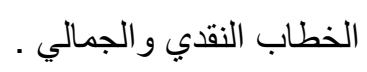

ان مفهوم الكتابة يمثل اثراً تناريخياً وهو يتشكل من مجمل مكونات الخطاب التاريخي: الرمز، التابو، الطقس او بين

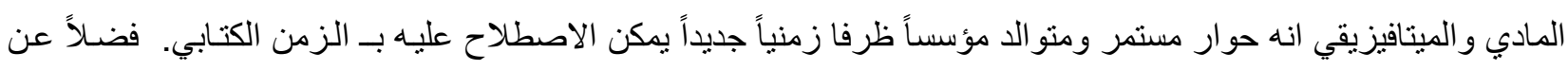

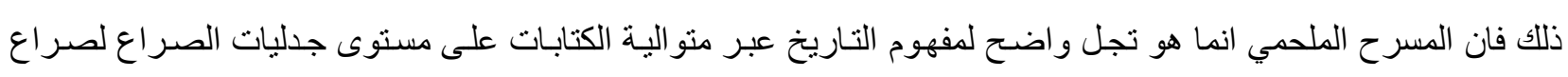
الطبقات ورأس المال ومفهوم الحرب عن طريق تاسيس فجوة تمتاز بايجابيتها في استيعاب مجمل الكتابات بين المتلقي وخطاب

$$
\text { r r }
$$

يمثل المعنى احد اقطاب تمثل مفهوم الكتابة بوصفه خاضعاً الى مرتكزين اساسيين:

$$
\text { r. }
$$

فالاول فعل لحظوي قائم على اشتخالات الثفرة ضمن جدلية العلامة ومفهومها الذي تجاوز مرحلة الاستقرار و الثبات

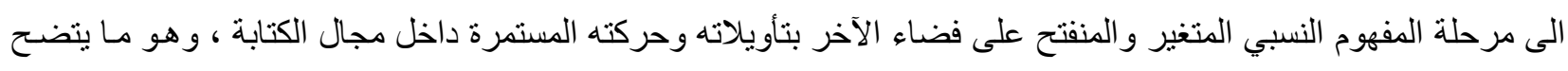

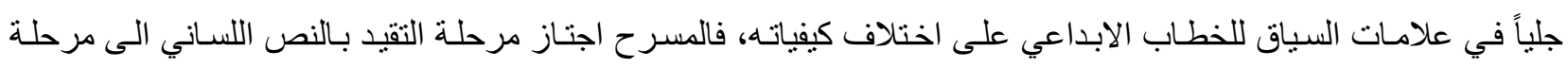

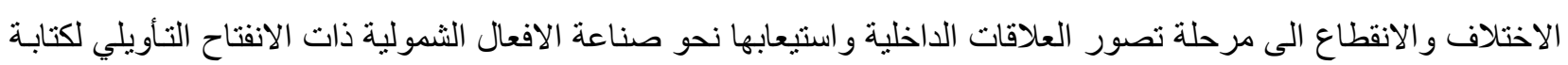

\section{$-919$.}


الاثر . اما المستوى الثاني، فان مفهوم الكتابة يعتمد في انشاء مجاله على تحويل المعنى من شكله المركزي الى فعل هامشي

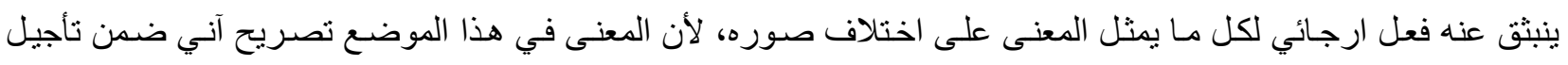

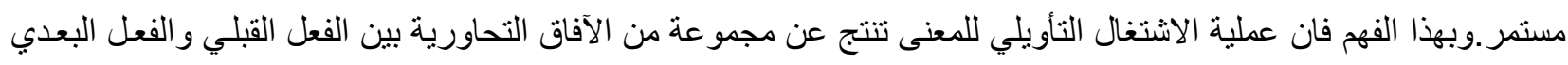

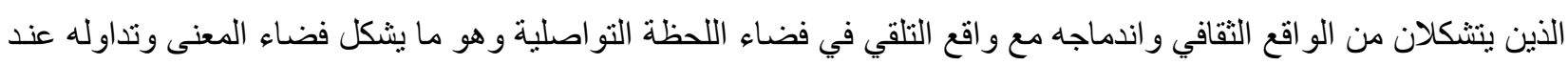
المتلقي في افق التوقع.

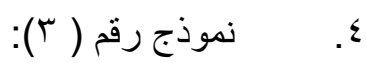

$$
\begin{aligned}
& \text { ○. المتلقي: }
\end{aligned}
$$

ضمن مفهوم الكتابة واجر اءاته فان التلقي عملية نموذجية ذات نمط خاص لا يخضع لأية سلطة غير الوعي، والمتلقي على وفق

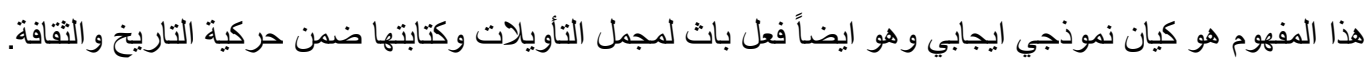
ان مفهوم الكتابة يستبعد توصيف الـ سلبي للمتلقي بكل ظروفه بهدف تفعيل عملية التحاور السلطوي للوعي بذاتيته وجمعيته على

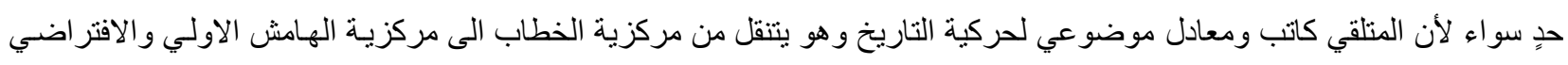

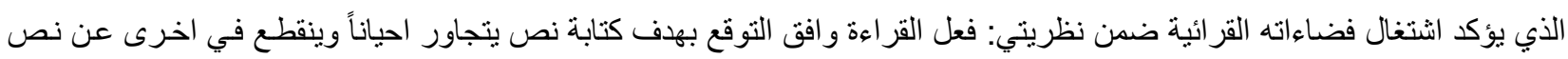

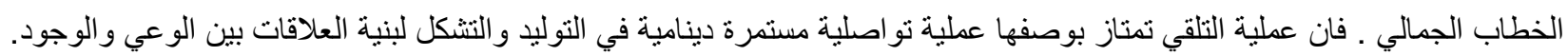

\section{نتائج البمث:}

ا. ـ الكتابة مجال ثثافي من التحاور بين العملية الإنسانية واشتغالاتها الجمالية، انها فجوة دائهة التواصل و التشكل والاختلاف وكما

$$
\text { هو في خطاب المسرح المعاصر مسرح اللامعقول ومسرح القسوة ل...الخ. }
$$

r. المعنى انزياح مستمر وحوار قائم على فعلي : الاختلاف والارجاء و وها فعلين يمتاز ان بالحركية المستمرة و النسبية والتتقل بين

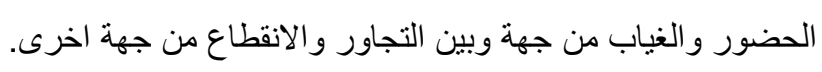

r. الكتابة مفهوم تو الدي دينامي مستمر في عملية التلقي للخطاب الجمالي، وهو نتاج لفعل قرائي تتبثق عنه افاق توقعية لجدلية

$$
\begin{aligned}
& \text { هواهش البحث }
\end{aligned}
$$

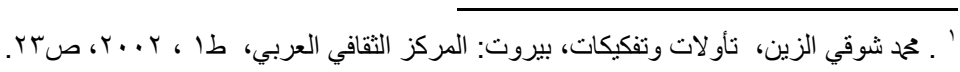

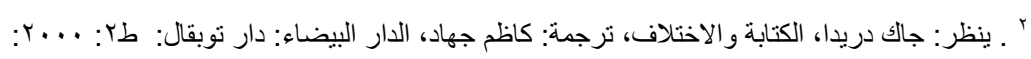

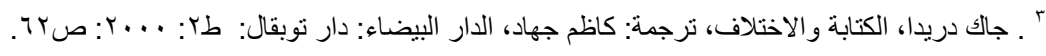

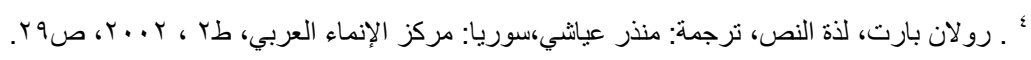

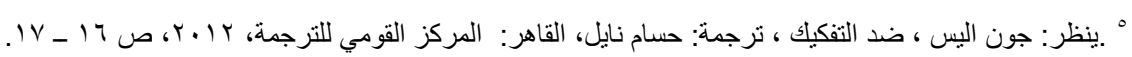

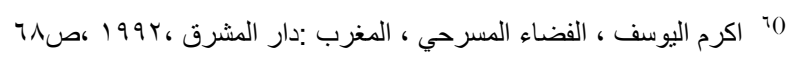

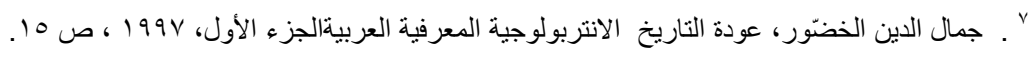

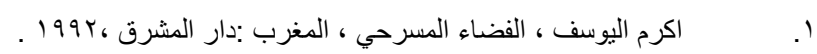

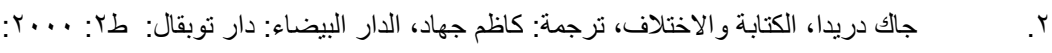

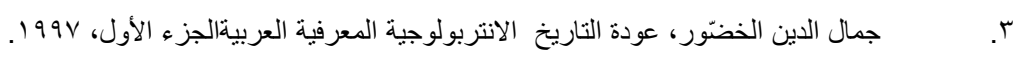

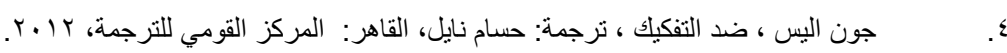

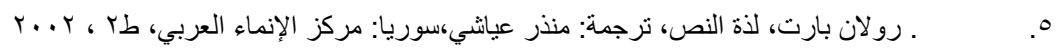

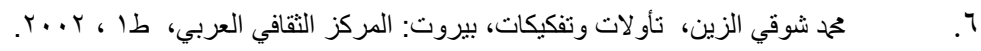

